\title{
The Limits of Law in Regulating Health Care Decisions
}

\author{
by ROBERT A. BURT
}

$\mathrm{T}$

he case for legal regulation of biomedical technology used to be easy to argue. A decade ago, it was clear that this technology had a dramatic impact on issues of far-reaching public significance, that many of these issues were not being systematically addressed by anyone, and that others were being considered only by physicians and biological scientists from a very narrow perspective. The argument for systematic law-making in the resolution of these issues was easy and, during the past few years, that argument seems in large part to have prevailed. Congressional establishment of the National Commission for Protection of Human Subjects of Behavioral and Biomedical Research, with its wide-ranging statutory jurisdiction, is one indication of this trend. The California "Natural Death Act" is another. A third indication is the current willingness of judges to enter into previously sacrosanct medical territory, to proclaim principles of "informed consent" for doctor/patient relations or "rights to treatment" for institutionalized mentally ill or retarded persons.

There is of course considerable controversy about the substance of these new legal rules. But there seems to be remarkable agreement on one underlying premise-that there should be new rules. Thus, although many doctors may be arguing for their traditional prerogatives to make treatment choices for their patients, few doctors are arguing against clarification of the rules by legislatures or courts.

This is the attitude that always underlies calls for some authoritative resolution of disputed matters-for law-making. There are, however, some special dangers in succumbing too readily to this attitude for many disputed issues. In advancing this view, I want to say a few words in praise of those much-maligned characters Uncertainty and Confusion, and their frequent companions Ambivalence, Anxiety, and even Irrationality.

\section{"Ideal" Parents as Objective Decision Makers}

Let me begin my argument in a context that has received some attention by law reform advocates-parental choice of medical care for children. Some legal rules are of course inevitably required to answer the question who decides

ROBERT A. BURT, J.D., is professor of law at Yale University. This article is adapted from a presentation delivered at the Institute's General Meeting, held June 17-18, 1977, and funded in part from a grant to the Humanities Program by The Rockefeller Foundation. medical care for children (even if the answer is that children decide for themselves). The traditional answer, with stringently limited exceptions, has been that parents decide. But that answer is under sustained assault today. The Supreme Court has already decided that parents may not veto their pregnant child's decision to have an abortion. No physician today will perform a kidney transplant between siblings without court approval of the parents' decision. Lower federal courts have ruled that parents may not place their child in a psychiatric institution unless an attorney is chosen to give the child independent represensation; if the adolescent child or the attorney for a younger child protests this psychiatric placement, a court must decide the matter.

The traditional rule has been called into question by the recognition that parents and children have ambivalent feelings toward one another, though "recognition" may be too mild a word to convey the sense of shock and even outrage that can be heard in current advocacy for law changes. The "discovery" of ambivalence between parent and child, of the possibility that their interests may conflict, is the perception expressed in court opinions and reformist literature in this matter, as if the traditional rule deferring to parental decisions were premised on a wholly benevolent and unambivalent attitude of parents toward children.

The law reform advocates reason thus: the ideal health care decision-maker is "objective," "rational," "detached." In those matters where parents are likely to be ambivalent and to have interests conflicting with their child's interests, parents no longer qualify as ideal decision makers. Accordingly, the argument runs, it is appropriate in these situations to have the decision made by an outsider who can more closely approximate the detached and rational ideal -a judge, that is, who guides his decisions by public norms in law.

This implicit praise of objectivity in decision making is the essential law-reform attitude. This ideal directly parallels, and has been significantly influenced by, the ethos of science itself, the ethos of objectivity in science. Current law reform efforts to interpose a judge between parent and child, in order to assure "rationality," "objectivity," "detachment" in health care decisions for the child, has its precise psychological analogy in the biomedical science's interposition of technology, of machines, between doctor and patient in order to vindicate the same supposed virtues.

Of course judges are not machines; neither are doctors. Both, however, have powerful professional role commitments to act like machines, to treat litigants or patients as interchangeable entities. This is not intended as a pejorative 
characterization. The ideal of equal justice under law, of assuring the governance of "laws not men," of treating "like cases alike" with fine impartiality expresses a conception of interchangeability on both sides of the legal relationship. These ideals suggest that a judge should be interchangeable with any other judge in reaching the same result for any litigant, just as any litigant should be interchangeable with any other before the same judge. Doctors equally hold to the normative proposition that any patient exhibiting symptom $A$ should be diagnosed as suffering from malady $\mathbf{B}$ and treated by therapeutic modality $\mathrm{C}$-no matter what the patient's religion, politics, or personal values.

Deviations from these computer-like norms occur every day among practitioners in both professions. But these deviations are not seen as occasions for self-congratulation, as virtues to be pursued, but rather as errors to be corrected, perhaps by appeal to a higher court or by recourse to a more certain diagnostic technique, or-if the highest court or best conceivable technique has ruled in the matter-as errors to be tolerated for the moment, but without pride.

The application of impersonal standards of judgment, in both law and medicine, is intended to guard against inappropriate conflicts of interest in a number of different senses. For judges and for doctors, the notion of "conflict of interest" has an obvious financial connotation-that a judge should not personally profit from his decision in litigation and, equally, that a physician should not choose surgery over nontreatment simply because he will earn more money from the surgical procedure. But there is a more profound underlying notion of interests in conflict for both professions. This notion is most evident in the norm that judges should not rule "in their own causes" and should have no direct personal stake in the outcome of the litigation. Judges are instructed, that is, to control-indeed, to banish-(as if that were possible) - their own narcissistic identifications with the litigants before them. Judges are directed by their professional norms to keep distance between themselves and those over whom they exercise authority, not to confuse themselves with those dependent on them.

This same norm for physicians has been explicitly promulgated in psychiatric practice where the injunction to scrutinize countertransference-the psychiatrist's emotional response to his patient-has both a technical therapeutic and a normative implication. The normative implication of this injunction, at least, is not limited to psychotherapy. The injunction purports to extend throughout medical practice, and it forms the ethical basis for the canon that a physician should solicit and respect the patient's wishes in treatment matters because the physician is not the patient, the patient is the patient. The professional impropriety seen in conflicts of interest between judge and litigant, or between doctor and patient, at base expresses the same normative instruction: don't confuse yourself with this person who is dependent on you.

This confusion of selves is, however, a classically observed and approved attribute of typical relations between parent and child. The intense bonding, the profound narcissistic identification, that exist between parent and child- experienced by both with special intensity during infancyhas traditionally been viewed as an essential defining characteristic of the relationship rather than as a psychological problem or aberration to be overcome. Nonetheless, here too the scientific ethos has significantly altered the way that parent/child relations are popularly perceived, even in the idea that children have "rights" which state officials should enforce against their parents.

In this century Freudian psychology offered the first systematic elaboration of the idea that children were not simply "unformed adults" who were to be shaped, even forced, to grow into human status, but that children's psychology had its own internal logic which commanded independent respect. Beginning in the 1920s and 30s in this country, and still today, parents have looked for advice about childrearing from professionals who spoke from this perspective. The notion of parenthood as a profession, of rules to be learned and expertise to be developed, was built on the premise that a "good parent" views his children with a clear-headed sense of their individuality and a careful respect for their "independent rights"-views them, that is, "objectively," "dispassionately."

This perspective readily lends itself to invitations for state superintendence of parental decisions where it appears that this norm of parental "objectivity" is under particular stress-kidney transplant between siblings, abortion for a pregnant child, psychiatric hospitalization for a child. This normative valuation of parental objectivity, of the "good parent" as the expert applier of the best-considered rules for childrearing, readily suggests the essential interchangeability of parents and judges. The "good parent," that is, behaves like a "good judge," and therefore a "good judge" can easily - indeed, interchangeably-evaluate what a "good parent" would do in any particular circumstance.

This new attitude is not drawn from statistically based inquiries into the prevalence of "good" or "bad" parental decisions in health care matters. The attention and the acceptance accorded to the new rule do not follow from a sudden discovery that more parents are "unwise" than had been supposed. Rather, these new rules seem plausible and even attractive because of a subtle shift in social attitudes which posits the interchangeability of parents and judgesthe normative objectification of the childrearing enterprise. The old legal rule conclusively presumed that parents spoke for children because that rule was built on the unquestioned psychological premise of a fundamental identity, a confusion of "selves" between parents and child. The new rules are not intended conclusively to displace parental authority to speak for children. But they build from a very different psychological normative premise: that it is important for parents to keep their conception of themselves quite separate from their conception of the children's "selves." From this perspective, proponents of the new rules are able to argue that little of value is lost, and much can be gained, by providing outside supervision of parental decisions when their capacity for keeping their self-conception, their self-interest, distinct from their child's separate interest and separate "self" might suffer greatest stress. 


\section{Objectivity in Physician-Patient Relationships}

I have sketched the subtle conceptual changes that have yielded norms of "objectivity" in parenthood because I think these same issues underlie current social attitudes toward regulation of the provision of medical care generally, toward relations betwen doctor and patient. The social roles of doctor and judge have become interchangeable in ways that parallel-and indeed anticipate-this phenomenon for parents. The intense bonding, the narcissistic identifications, the confusions of "selves" which are paradigmatic in the parent/infant relationship also powerfully reverberate in traditional notions of charismatic medicine, the magical "laying on of hands" that brings psychological relief and physical cure to desperately ill patients. The development of scientific medicine sits with great discomfort alongside this more ancient healing tradition. Scientific medicine cannot ignore the claims of the ancient healing arts, if only because the placebo effect has been verified by the rigorous norms of empirical observation that are the very foundation of scientific medicine. But the scientific observational method itself posits a separation between the observer and the external world, between the scientist and his subject, between the doctor and his patient that cuts against the psychology of charismatic medicine. This scientific ethos does not yield comfortably to the contradictory psychological premises of reciprocally merged ego boundaries that are characteristic both of charismatic medicine and of charismatic parenting. To a rigorous biological scientist, this "confusion of selves" between two separate people is just that-a confusion, an irrationality, madness even.

Scientific medicine has had great triumphs in the past half-century. Its mechanistic, impersonal assumptions about the functioning of the human body have led to impressive therapeutic advances. The end of these advances and the continued vitality of these underlying assumptions are not yet in sight. It is, however, a commonplace criticism of scientific medicine that its practitioners, because of their objectifying mind-set, rivet attention on the disease and lose sight of the patient. There is thus at least some paradox that those who complain of impersonal, dehumanized medicine turn now for remedies to the legal system that prizes its systematic impersonality, its governance by laws not men.

But there is more than paradox here. For in the effort to rationalize, to bring order to the relationship between doctor and patient or parent and child, I believe we are disregarding and even loosening the central psychological bonds that have kept in check some extraordinarily destructive forces implicit in these relationships. The very attempt to order these relations implies an assumption that may seem self-evident-that the relationship is a transaction between two separate people. But this assumption is not necessarily self-evident to the participants. There are in fact powerful forces inevitably at work in the psyches of both doctor and patient, both parent and child, that deny this psychological separateness between them. The sense of boundaries can be maintained-quite rigorously, indeed -if this separate self-conception is sufficiently valued. The maintenance of such rigorous boundaries has not only a liberating and humane implication, but is also the psychological precondition for infliction of extraordinary brutality.

\section{The Brutality of Separation of Self}

This point is graphically demonstrated in a series of experiments conducted several years ago by Stanley Milgram. Milgram's subjects were led to believe that they were conducting learning experiments which required them to administer electric shocks of mounting severity to another person, a "learner," to induce him to memorize certain word associations. During the experiment, the supposed learner objected in varying ways to the administration of these shocks; when the subjects questioned whether they should continue, a laboratory technician supposedly in charge of the experiment instructed them to proceed. A considerable proportion of the subjects did so, inflicting on the first-protesting and then-silent learner shocks that were apparently severe enough to kill him.

In several ways these experiments suggest the proposition I am advancing about the inhumane implications of rigid separation of self from others. First, the subjects' willingness to obey the technician's directives, and to continue administration of the electric shocks, varied systematically depending on their physicial proximity to the learner. Almost two-thirds of the subjects followed the directives, though not without protest and visible strain, when the learner/victim was in another room, while about one-third of the subjects were willing to continue the shocks when the learner/victim was seated beside them and they were required to press his hand onto a metal plate to administer the shocks.

But even this latter result is astounding testimony to the inhumane potential in people. The critical question is how this potential was activated. The likely answer suggests a second brutalizing implication of the psychology of science, of the "objective observer." I believe the answer is to be found in the rigid separation between self and other that the subjects were able to maintain by believing that their actions did not "belong" to them at all, that their actions in fact "belonged" to the technician who, in response to their protests or questions, repeatedly accepted "full responsibility" for the actions. These subjects, that is, depersonalized themselves, made themselves into objective instruments, rule-followers, embodiments of the scientific method in order to silence that part of their psyches that empathized with the learner/victim, that confused the question whether he was separate from or the same as them.

The third aspect of these experiments that demonstrates the brutal implications of the scientific ethos is the fact that the experiments were conducted at all. The subjects were not alone in inflicting shocks on a victim whom they had good reason to believe would suffer greatly from their actions. Milgram and his associates acted in the same way for several years with several thousand different subjects. Milgram claims that his follow-up studies of these sub- 
jects indicate that none has suffered any adverse psychological consequences from his participation, whether or not he obeyed the technician's directives to administer the ultimate shock levels. But during the conduct of these experiments, the subjects all showed extreme stress, and Milgram could not then have known with any certainty that no adverse consequence would result.

The learner/victim of course was an actor and the shocks were faked, and so deception was added to the other indignities generously heaped on the subjects by the experimenter. The central lesson, however, does not lie in the deception practiced by Milgram; it lies rather in the deception that all these participants practiced on themselves. Though three human beings participated in each of these experiments-the subject, the learner/victim, and the experimenter-there were no fully flesh-and-blood people there. There were only three actors pretending to be someone else, to be somewhere else; no one accepted responsibility for truly being there, for feeling another's pain as if it were his own. No one accepted personal responsibility for the actions that inflicted visible pain on the other. This is the ultimate expression of, and the ultimate parody of, a government of laws not men.

\section{The Dangers of Rationality}

This same brutal parody potentially lies within many proposed legal reforms to regulate biomedical technology. The physician who is now instructed to obey the "informed consent" of his patient, no matter how harmful he feels that action to be for the patient, is not only permitted but positively enjoined to separate himself from his patient, to respect his patient's "autonomy" by suppressing his own identifications, his self-confusions, with that patient. The danger here is not so much in the norm as in overpunctilious compliance with the norm. Thus, when the patient formerly said, "I want to die," the traditional practitioner acted as if no one had spoken, and proceeded as if he, the doctor, were the patient and the patient were not there at all as a separate human being. I hold no brief for this rigidly single-minded narcissism.

But the underlying impetus of the new legal reforms under the banner of "patient autonomy" presses to the opposite extreme, that the doctor should act as if he were not there at all but must simply obey the patient's directives as Milgram's subjects conceived themselves to have no choice but to obey the technician. Thus when the patient requests death from a doctor schooled in this new regime, the danger is that the doctor will comply with great rigor and haste, and even moralistic self-righteousness. He will do so in order to keep intact the rigidly separated roles prescribed for each, in order to reassure himself that he is not the patient, to reassure himself that he does not feel the terror and pain that the patient feels, to reassure himself that he will not die because it is only the patient who will die.

Similarly, when a judge supervises parental decisions and thus accepts apparent responsibility for the decision whether a child should donate his kidney to a sibling or whether a comatose child's respirator should be disconnected, the judge can act with the comforting knowledge that he and this child are quite separate from one another - that the child is not his, that the consequences of this decision will not shape his family's life and his self-conception forever, that he is after all only applying "the rules" with an impartial eye or even, as the popular image of Lady Justice suggests, with blindfolded eyes. The parents and doctors can also reassure themselves with this same false comfort-that they are not personally responsible for their actions toward the child, but that someone else accepts that responsibility-someone who, like Milgram's technician, himself disclaims any personal responsibility for his actions.

From this perspective, it is not surprising that the judges of the New Jersey Supreme Court purported to resolve the issue in Karen Quinlan's case by proclaiming their reliance on the wishes of someone who was clearly not thereKaren herself, that is, whom the judges explicitly imagined might wake up for a moment and announce that she wanted her pain to end. It was of course not clear that in her comatose state Karen was feeling any pain. Her parents were feeling pain, as were her doctors and the judges. But the law encouraged all of them to avoid the recognition that they were confusing themselves with her by ascribing their pain to her. They could avoid this recognition and the anxiety that comes from unresolved ambivalence by accepting the law's invitation to pretend that no one was there but the rule of law.

I have presented a one-sided argument, and thus perhaps conveyed a misleading impression of my own evaluation of the excesses and brutalities implicit in the traditional claims of physicians and parents for unquestioned authority over their patients and children. I have not stressed this side of the argument because I believe that it has been effectively conveyed during the past decade-too effectively, too single-mindedly, in my view. The psychological premises that underlie the traditionalist and the reformist attitudes-whether doctors or parents are psychologically separate from or share identities with those dependent on their care-stand in fundamental contradiction. But the great danger lies, I believe, in forcing a choice of one mind-set to the exclusion of the other. I think that the present turmoil-the anxiety among doctors and parents, among patients and children, about their proper relations with one another-is the most fruitful and protective posture for everyone. It is in this sense that I intend, as I said at the beginning of this article, to praise Confusion and Uncertainty.

Law-makers-legislators or judges-have notoriously little tolerance for confusion. Biomedical scientists, schooled in the objective techniques of modern science, are equally averse to disorder. But their impulse to bring rational order to the social deployment of biomedical technology has inhumane and brutalizing implications. We should view this impulse with suspicion. It does not necessarily control the dehumanizing aspects of scientific technology, but can readily lead us to be controlled by the mechanistic imperatives of the technology itself. 